\title{
ANALISIS KINERJA TURBIN UAP BERDASARKAN PERFORMANCE TEST PLTU PT. INDOCEMENT P-12 TARJUN
}

\author{
Riyki Apriandi'1), Aqli Mursadin'2) \\ 1,2Program Studi Teknik Mesin \\ Fakultas Teknik Universitas Lambung Mangkurat \\ Jl. Akhmad Yani Km. 36 Banjarbaru, Kalimantan Selatan, 70714 \\ Telp. 0511-4772646, Fax 0511-4772646 \\ E-mail: Rezkiapriandi@gmail.com
}

\begin{abstract}
This study aims to determine the performance of steam turbine PT. Indocement Tarjun Plant 12 by comparing the results of data obtained during each performance test in 1999, 2016, 2017, and 2018. This research data is taken from the control room of PT. Indocement Tarjun, variable data obtained in the form of load, main inlet steam temperature, main inlet steam pressure, HP heater feed outlet temperature, HP heater feed outlet pressure, main steam flow, and turbine by pass flow. The data is processed to get the turbine heat rate and the efficiency per time of each performance test and then averaging the data results over time, then comparing the turbine heat rate and the average efficiency of each performance test. The calculation of turbine heat rate using heat \& mass balance method, turbine efficiency is obtained by comparing the energy of $1 \mathrm{~kW}$ with turbine heat rate and multiplying $100 \%$. The result of the average heat turbine calculation per performance test ie August 1999 is 2.546, April 2016 2,537, June 2017 2.56, and May 2018 2.67. The average value of turbine efficiency in August 1999 was 39.30\%, April 2016 39.43\%, June 2017 39.07\%, May 2018 37.46\%. Turbine power plant performance of PT Indocement Tarjun Plant 12 decreased from 1999 to 2018 by $1.84 \%$.
\end{abstract}

\section{Keywords : Turbine Heat Rate, Efisiensi Turbin, Heat \& Mass Balance}

\section{PENDAHULUAN}

Energi sangat dibutuhkan untuk kehidupan manusia, salah satu energi yang diperlukan untuk menunjang kehidupan manusia yaitu energi listrik. Energi listrik diperlukan manusia untuk berbagai keperluan baik itu untuk kepentingan rumah tangga, industri, dan prasarana lainnya. Energi listrik yang besar serta penggunaannya yang terus menerus tidak dapat tersedia secara alami. Oleh sebab itu dibutuhkan pembangkit listrik yang handal.

PLTU yang ada di Tarjun, Kotabaru, Kalimantan selatan merupakan pembangkit listrik yang dimiliki oleh perusahaan PT. Indocement Tunggal Prakarsa tbk Tarjun Plant 12, dimana mempunyai kapasitas 55 MW. Listrik yang dihasilkan digunakan untuk memenuhi kebutuhan tenaga listrik bagi cement plant dan fasilitas-fasilitas pendukungnya.

Turbin uap adalah mesin konversi energi dengan mengkonversikan energi kalor menjadi energi mekanik, dan energi mekanik menjadi energi listrik pada generator. Performance test dilakukan untuk mengatahui heat rate pada turbin di PLTU. Heat rate pada PLTU dapat di hitung dengan metode efisiensi boiler (metode input output dan metode kehilangan panas), turbine heat rate, dan specifik fuel consumption (SFC).

PLTU yang digunakan pada suatu pembangkit tidak sepenuhnya energi uap yang dihasilkan dapat diubah menjadi $100 \%$ output energi mekanis pada turbin, karena akan ada sebagian kehilangan energi yang dapat disebabkan 
kebocoran dan suplai uap yang tidak maksimal pada kondensor sehingga menyebabkan kinerja pada turbin uap menurun. Performance test dilakukan untuk menghitung besarnya energi panas yang dihasilkan untuk memproduksi listrik $1 \mathrm{kWh}$ yang digunakan untuk memutar turbin.

Dari latar belakang masalah tersebut perlu dilakukan analisis yang berhubungan dengan kinerja pada turbin uap yaitu dengan judul "Analisis Kinerja Turbin Uap Berdasarkan Performance Test PLTU PT. Indocement Tunggal Prakarsa Tbk P-12 Tarjun- Kalimantan Selatan" untuk mengetahui turbine heat rate dan efisiensi pada turbin lalu membandingkan hasil data yang didapat pada setiap performance test.

\section{Proses Konversi Energi}

Pembangkit Listrik Tenaga Uap (PLTU) PT Indocement Tunggal Prakarsa Tbk Tarjun Plant 12 merupakan pembangkit listrik dengan bahan bakar batubara yang memanfaatkan fluida kerja berupa uap (steam) untuk menggerakkan turbin yang bertindak sebagai penggerak mula yang kemudian turbin akan memutar rotor generator untuk menghasilkan listrik. Dalam proses produksi listrik, banyak terjadi proses konversi energi. Proses konversi energi sendiri merupakan proses perubahan energi berdasarkan perubahan bentuk dan sifatnya. Berawal dari energi kimia yang terkandung dalam barubara yang dikonversi menjadi energi kalor dalam proses pembakaran. Kemudian dikonversi lagi menjadi energi kinetik berupa aliran uap (steam), selanjutnya dikonversi menjadi energi mekanik melalui putaran turbin dan pada proses akhirnya energi mekanik tersebut dikonversikan menjadi energi listrik melalui generator.
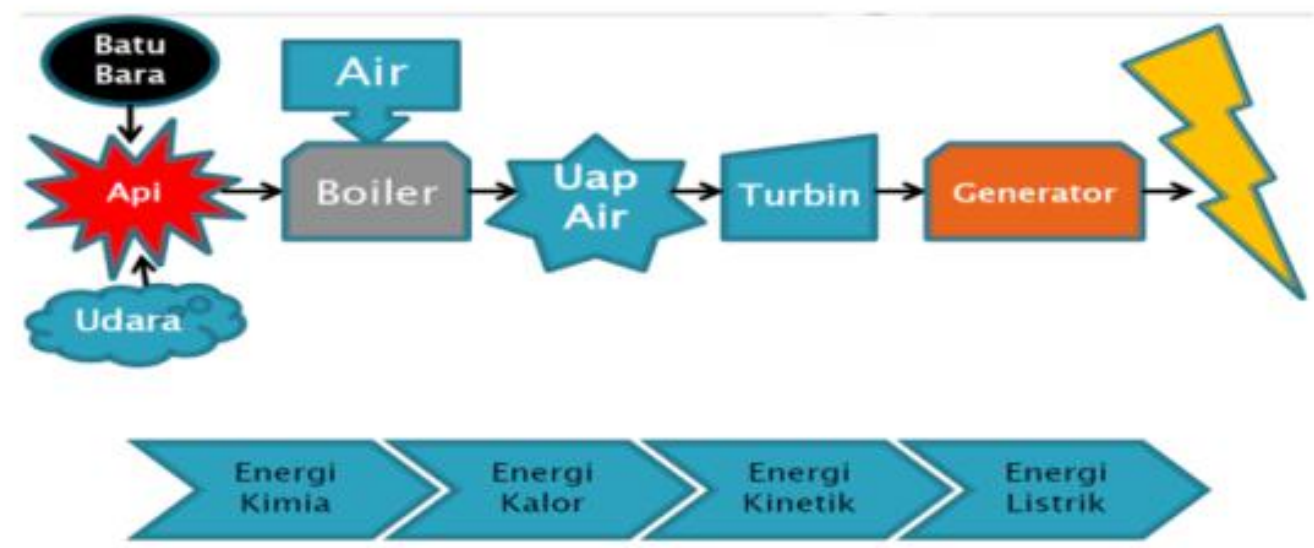

\section{Gambar 1. Proses Koversi Energi PLTU}

\section{Turbin}

Turbin merupakan salah satu mesin konversi yang mengubah energi aliran suatu fluida menjadi energi gerak yang dapat dimanfaatkan. Mesin turbin terdiri dari beberapa bagian salah satunya rotor yang merupakan bagian berputar terdiri dari poros/ shaft dengan sudu - sudu disekelilingnya. Tumbukan pada aliran fluida menyebabkan rotor berputar.

Terdapat dua jenis turbin, yaitu turbin implus dan turbin reaksi. Pada turbin implus, rotor berputar karena tumbukan dari fluida yang diarahkan oleh nosel. Sedangkan pada turbin reaksi rotor berputar karena tekanan fluida uap dari nosel yang keluar pada ujung - ujung sudu. 


\section{Turbin Uap}

Turbin uap merupakan suatu penggerak mula yang mengubah energi potensial uap menjadi energi kinetik dan selanjutnya diubah menjadi energi mekanis dalam bentuk putaran poros turbin. Poros turbin, lansung atau dengan bantuan roda gigi reduksi, dihubungkan dengan mekanisme yang akan digerakkan. Tergantung pada jenis mekanisme yang digunakan, turbin uap dapat digunakan pada berbagai bidang seperti pada bidang industri, untuk pembangkit tenaga listrik dan untuk transportasi. Pada proses perubahan energi potensial menjadi energi mekanisnya yaitu dalam bentuk putaran poros dilakukan dengan berbagai cara. Salah satu turbin uap yang digunakan di PLTU ditunjukkan dalam Gambar 2.

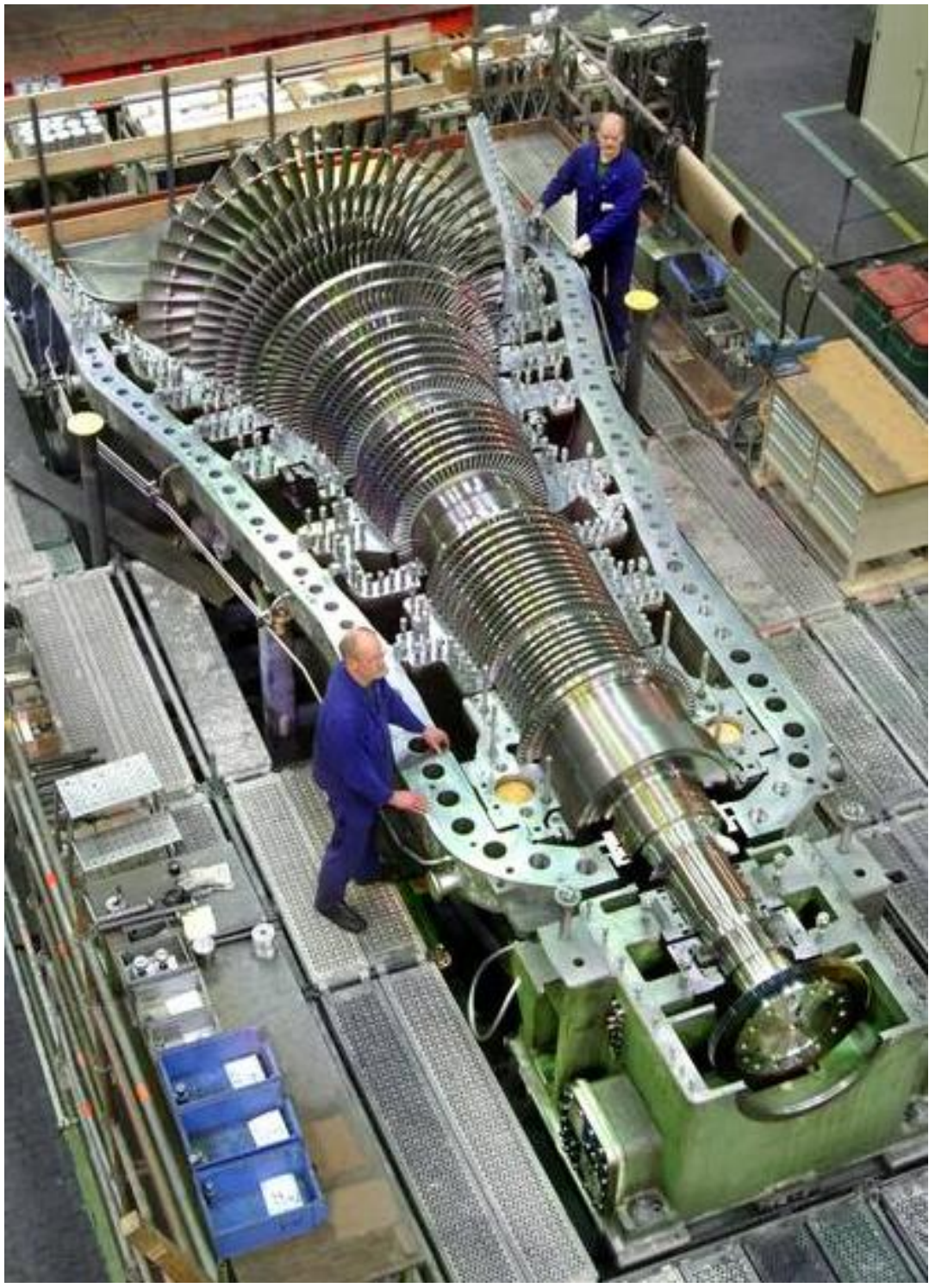

Gambar 2. Tubin Uap

Pada dasarnya turbin uap terdiri dari dua bagian utama, yaitu stator dan rotor yang merupakan komponen utama pada turbin kemudian di tambah komponen lainnya yang meliputi pendukungnya seperti bantalan, kopling dan sistem bantu lainnya agar kerja turbin dapat lebih baik. Sebuah turbin uap memanfaatkan energi kinetik dari fluida kerjanya yang bertambah akibat penambahan energi termal. 
Turbin uap adalah suatu penggerak mula yang mengubah energi potensial menjadi energi kinetik dan energi kinetik ini selanjutnya diubah menjadi energi mekanik dalam bentuk putaran poros turbin. Poros turbin langsung atau dengan bantuan elemen lain, dihubungkan dengan mekanisme yang digerakkan. Tergantung dari jenis mekanisme yang digerakkan turbin uap dapat digunakan pada berbagai bidang industri, seperti untuk pembangkit listrik.

Sebuah sistem turbin uap - generator yang digunakan untuk pembangkit listrik tenaga uap berfungsi untuk mengkonversikan energi panas dari uap air menjadi energi listrik. Proses yang terjadi adalah energi panas yang ditunjukkan oleh gradien/perubahan temperatur dikonversikan oleh turbin menjadi energi kinetik dan sudu-sudu turbin mengkonversikan energi kinetik ini menjadi energi mekanik pada poros/shaft. Pada akhirnya, generator mengkonversikan energi mekanik menjadi energi listrik. Panas dari uap air yang tidak terkonversi menjadi energi mekanik, terdisipasi/dibuang di kondenser oleh air pendingin.

Umumnya PLTU menggunakan turbin uap tipe multistage, yakni turbin uap yang terdiri atas lebih dari 1 stage turbin (Turbin High Pressure, Intermediate Pressure, dan Low Pressure). Uap air superheater yang dihasilkan oleh boiler masuk ke turbin High Pressure (HP), dan keluar pada sisi exhaust menuju ke boiler lagi untuk proses reheater. Uap air yang dipanaskan kembali ini dimasukkan kembali ke turbin uap sisi Intermediate Pressure (IP), dan uap yang keluar dari turbin IP akan langsung masuk ke Turbin Low Pressure (LP). Selanjutnya uap air yang keluar dari turbin LP masuk ke dalam kondenser untuk mengalami proses kondensasi.

\section{Komponen-Komponen Turbin Uap}

Berikut adalah beberapa bagian-bagian penting dari turbin uap:

\section{Shaft Seal}

Shaft seal adalah bagian dari turbin antara poros dengan casing yang berfungsi untuk mencegah uap air keluar dari dalam turbin melewati sela-sela antara poros dengan casing akibat perbedaan tekanan dan juga untuk mencegah udara masuk ke dalam turbin (terutama turbin LP karena tekanan uap air yang lebih vakum) selama turbin uap beroperasi.

Turbin uap menggunakan sistem labyrinth seal untuk shaft seals. Sistem ini berupa bagian yang berkelak-kelok pada poros dan casing-nya yang kedua sisinya saling bertemu secara berselang-seling. Antara labyrinth poros dengan labyrinth casing ada sedikit rongga dengan jaraj tertentu. Sistem ini bertujuan untuk mengurangi tekanan uap air di dalam turbin yang masuk ke sela-sela labyrinth sehingga tekanan antara uap air dengan udara luar akan mencapai nilai yang sama pada titik tertentu. Selain adanya sistem labyrinth seal, ada satu sistem tambahan bernama sistem seal \& gland steam. Sistem ini bertugas untuk menjaga tekanan di labyrinth seal pada nilai tertentu terutama pada saat start up awal atau shut down turbin dimana pada saat tersebut tidak ada uap air yang masuk ke dalam turbin uap.

\section{Turbine Bearings}

Bearing / bantalan pada turbin uap memiliki fungsi sebagai berikut:

a. Menahan diam komponen rotor secara aksial Menahan berat dari rotor Menahan berbagai macam gaya tidak stabil dari uap air terhadap sudu turbin.

b. Menahan gaya kinetik akibat dari sisa-sisa ketidakseimbangan atau ketidakseimbangan karena kerusakan sudu (antisipasi).

c. Menahan gaya aksial pada beban listrik yang bervariasi. 
d. Jenis bearing yang digunakan dalam desain turbin uap yaitu thrust bearing, journal bearing, dan kombinasi antara keduanya. Selain itu juga dibutuhkan sebuah sistem pelumasan menggunakan oli, yang secara terus-menerus disirkulasi dan didinginkan untuk melumasi bearing yang terus mengalami pergesekan pada saat turbin uap beroperasi normal.

\section{Balance Piston}

Pada turbin uap, ada $50 \%$ gaya reaksi dari sudu yang berputar menghasilkan gaya aksial terhadap sisi belakang dari silinder pertama turbin, gaya inilah yang perlu dilawan oleh sistem balance piston.

\section{Turbine Stop Valves}

Atau disebut juga Emergency Stop Valve karena berfungsi untuk mengisolasi turbin dari supply uap air pada keadaan darurat untuk menghindari kerusakan atau juga overspeed.

\section{Turbine Control Valve}

Berfungsi untuk mengontrol supply dari uap air yang masuk ke dalam turbin sesuai dengan sistem kontrol yang bergantung pada besar beban listrik.

\section{Turning Device}

Adalah suatu mekanisme untuk memutar rotor dari turbin pada saat start awal atau pada saat setelah shut down untuk mencegah terjadinya distorsi/bending akibat dari proses pemanasan atau pendinginan yang tidak seragam pada rotor.

\section{Prinsip Kerja Turbin Uap}

Prinsip kerja turbin uap, yaitu :

a. Tekanan uap yang masuk ke nosel lebih besar dibandingkan tekanan uap yang keluar dari nosel. Sudu- sudu turbin berputar karena adanya tumbukan dari uap yang keluar dari nosel.

b. Turbin dipasang beberapa sudu gerak, sudu tetap disetiap baris kedua sudu gerakan, agar energi kinetik yang tersisa saat meninggalkan sudu turbin dapat dimanfatkan kembali. Sudu tetap berfungsi mengubah arah kecepatan uap, agar uap dapat masuk kembali ke garis sudu gerak dengan tepat (Putra Iriansyah, 2013).

c. Untuk mendapatkan efisiensi turbin yang lebih tinggi, maka harus dibuat sekecil mungkin kecepatan uap saat meninggalkan sudu gerak turbin terakhir, agar energi kinetik yang ada dapat lebih dimanfaatkan untuk meminimalkan kehilangan energi (Putra Iriansyah, 2013). 


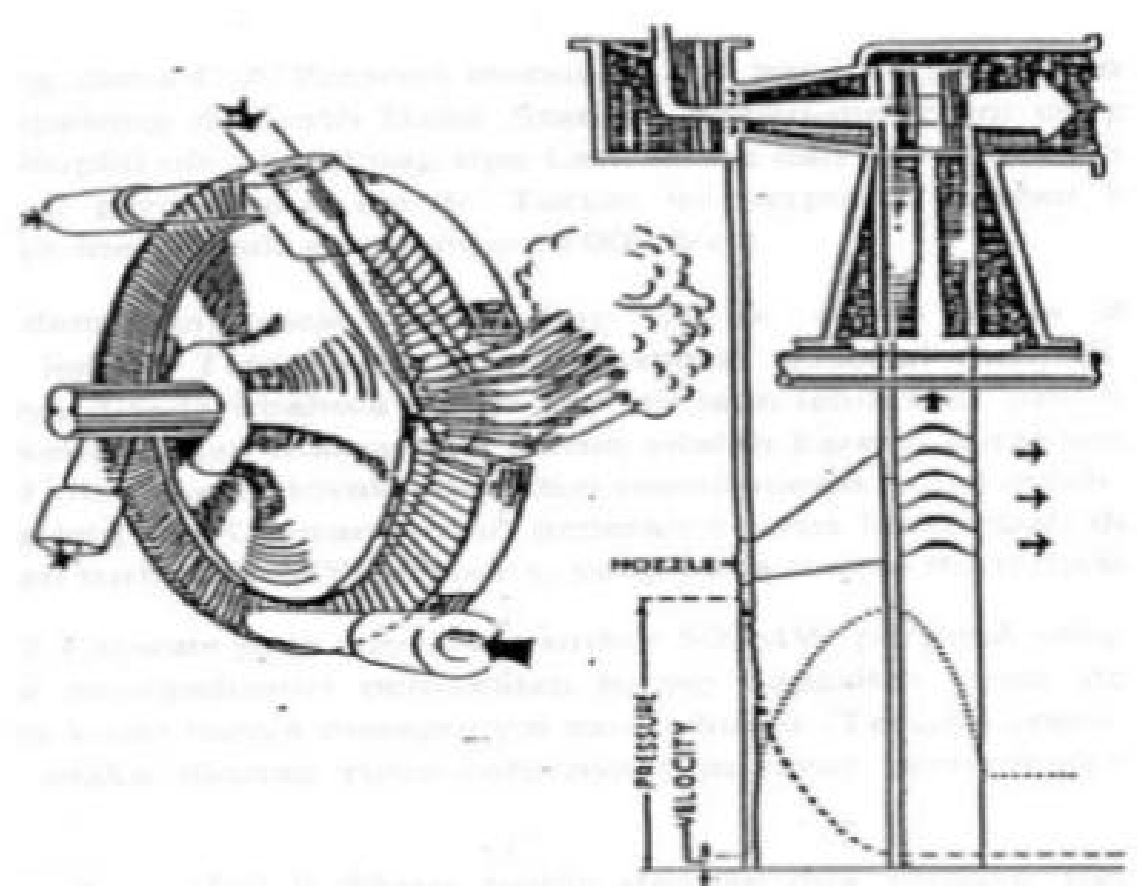

Gambar 3. Prinsip Kerja Turbin Uap

\section{Heat Rate}

Heat rate merupakan jumlah energi yang dibutuhkan untuk memproduksi listrik sebesar $1 \mathrm{kWh}$. Heat rate merupakan tolak ukur untuk membandingkan nilai energi input dengan energi yang dihasilkan dalam $1 \mathrm{kWh}$. Nilai heat rate sangat penting untuk mengukur biaya operasi suatu PLTU, heat rate juga digunakan sebagai tolak ukur performa kerja dari suatu PLTU.

Terdapat dua metode untuk menentukan heat rate PLTU yaitu dengan metode input - output dan metode energy - balance. Metode input - output adalah metode dengan mengukur energi input dari bahan bakar yang digunakan selama proses pengujian lalu membandingkan nya dengan energi listrik yang dibangkitkan. Metode enrgy - balance lebih rumit karena harus menghitung loses - loses pada setiap bagian pembangkit dengan menggunakan formula formula perhitungan rumit. Pada PLTU ada beberapa pengukuran heat rate yang digunakan untuk perhitungan yaitu turbine heat rate (THR), gross plant heat rate (GPHR), dan net plant heat rate (NPHR).

\section{Turbin Heat Rate}

Turbine heat rate merupakan perhitungan perbedaan heat dari parameter fluida yang masuk dan keluar pada boiler atau total laju heat yang masuk pada suatu siklus uap. Turbine heat rate menunjukan perbandingan dari energi total yang digunakan untuk memutar turbin, dengan energi listrik nett yang dihasilkan oleh generator.

Turbine Heat Rate dapat dikalkulasi dengan persamaan :

$T H R=\frac{\dot{m}_{1}\left(h_{1}-h_{2}\right)}{\text { Gross Output }}$

Dimana

THR : Heat Rate Turbin

$\dot{m}_{1} \quad$ : Laju Aliran Massa Fluida $(\mathrm{kg} / \mathrm{s})$

$h_{1} \quad:$ Enthalpy Steam Out Boiler $(\mathrm{kJ} / \mathrm{kg})$

$h_{2} \quad$ :Enthalpy Water In Boiler $(\mathrm{kJ} / \mathrm{kg})$

Gross Output : Power Output Generator (kW) 


\section{Gross Plant Heat rate}

Gross Plant Heat rate dapat dihitung dengan membandingkan bahan bakar dimasukkan ke boiler dengan gross output generator (Pembangkitlistrik.com, 2015). Formulasi untuk menghitung GPHR adalah

$$
\begin{array}{ll}
\text { GPHR }=\frac{\text { Cv Bahan Bakar } x \text { Flowrate }}{\text { Gross Output }} \\
\text { Dimana } & : \text { Gross Plant Heat Rate } \\
\text { GPHR } & \text { Nilai Kalori Bahan Bakar }(\mathrm{kJ} / \mathrm{kg}) \\
\text { Cv Bahan Bakar } & : \text { Laju Aliran Bahan Bakar }(\mathrm{kg} / \mathrm{s}) \\
\text { Flowrate } & : \text { Power Out Generator }(\mathrm{kW})
\end{array}
$$

\section{Nett Plant Heat rate}

Nett Output merupakan selisih dari daya/ power total yang dihasilkan suatu pembangkit dengan pemakaian daya/ power sendiri (auxiliary power) pada peralatan - peralatan pembangkit seperti pompa, kompressor, kondensor, dll. Formulasi perhitungan nett plant heat rate adalah :

$$
\begin{aligned}
& N P H R=\frac{G P H R}{(1-\text { Aux. Power } / \text { Gross Output })} \\
& \text { Dimana } \\
& \text { NPHR : Net Plant Heat Rate } \\
& \text { GPHR : : Gross Plant Heat Rate } \\
& \text { Aux Power : Dava Untuk Pembangkat (kW) } \\
& \text { Gross Output : : Power Out Generator (kW) }
\end{aligned}
$$

Efisiensi turbin merupakan parameter yang menyatakan derajat keberhasilan komponen atau sistem turbin mendekati desain atau proses ideal dengan satuan \%. Efisiensi turbin dapat dihitung dengan formula sebagai berikut:

$\eta=\frac{\text { Energi Kalor dalam } 1 \mathrm{kWh}}{\text { Heat Rate Turbin }} \times 100 \%$

Dimana

$\eta$

Enegi kalor $1 \mathrm{kWh} \mathrm{:} 3600 \mathrm{~kJ}$

Efisiensi turbin \%

\section{Metode Penelitian}

Metode yang digunakan pada penulis untuk menentukan kinerja turbin uap PLTU PT. Indocement P-12 Tarjun adalah :

1. Metodologi Pengumpulan data

Pengumpulan data performance test didapat pada komputer kontrol di CCR. Data yang di dapat berupa main inlet steam temperature $\left(T_{0}\right)$, hp heater feed outlet temperature $\left(\mathrm{T}_{\mathrm{fw}}\right)$, main inlet steam pressure $\left(\mathrm{P}_{\mathrm{o}}\right)$, $\mathrm{hp}$ heater feed outlet pressure $\left(\mathrm{P}_{\mathrm{fw}}\right)$, main steam flow $(\dot{m})$, Load dan bypass flow $(\dot{m})$.

2. Metodologi Pengolahan Data

Metode pengolahan data dari penelitian ini yaitu data yang diperoleh dari penelitian diolah secara manual menggunakan formula - formula. 


\section{HASIL DAN PEMBAHASAN}

Pada analisis kinerja turbin uap ini data yang diambil merupakan data performance test PLTU PT. Indocement P-12 Tarjun Agustus 1999, April 2016, Juni 2017, Mei 2018.

Tabel 1. Hasil Perhitungan rata - rata turbine heat rate dan efisiensi turbin

\begin{tabular}{|c|c|c|c|}
\hline No & $\begin{array}{c}\text { Performance } \\
\text { Test }\end{array}$ & THR & $\eta(\%)$ \\
\hline $\mathbf{1}$ & Agustus 1999 & 2,546 & 39,30 \\
\hline $\mathbf{2}$ & April 2016 & 2,537 & 39,43 \\
\hline $\mathbf{3}$ & Juni 2017 & 2,56 & 39,07 \\
\hline $\mathbf{4}$ & Mei 2018 & 2,67 & 37,46 \\
\hline
\end{tabular}

\section{Turbine Heat Rate dan Efisiensi Turbin}

Data yang didapat pada setiap performance test diolah/dihitung turbine heat rate dan efisiensi turbin disetiap titik/ waktu pengambilan data, kemudian merata- ratakan hasil data keseluruhan.

a. Perhitungan turbine heat rate (THR) dari data performance test Agustus 1999 jam 09.45

$$
\begin{aligned}
\text { THR } & =\frac{\dot{m}\left(h_{o}-h_{f w}\right)}{\text { Gross Output }} \\
& =\frac{45,64(3417,73-838,86)}{46000 \mathrm{~kW}} \\
& =\frac{45,64(2578,87)}{46000 \mathrm{~kW}} \\
& =2,559
\end{aligned}
$$

b. Perhitungan efisiensi turbin dari data performance test Agustus 1999 jam 09.45

$$
\begin{aligned}
\eta & =\frac{3600 \mathrm{~kJ}}{T H R} \times 100 \% \\
& =\frac{1 \mathrm{~kW}}{2,615} \times 100 \% \\
& =39,08 \%
\end{aligned}
$$

Perbandingan turbin heat rate dan efisiensi turbin rata - rata setiap tahun ditunjukan pada Gambar 4 dan Gambar 5.

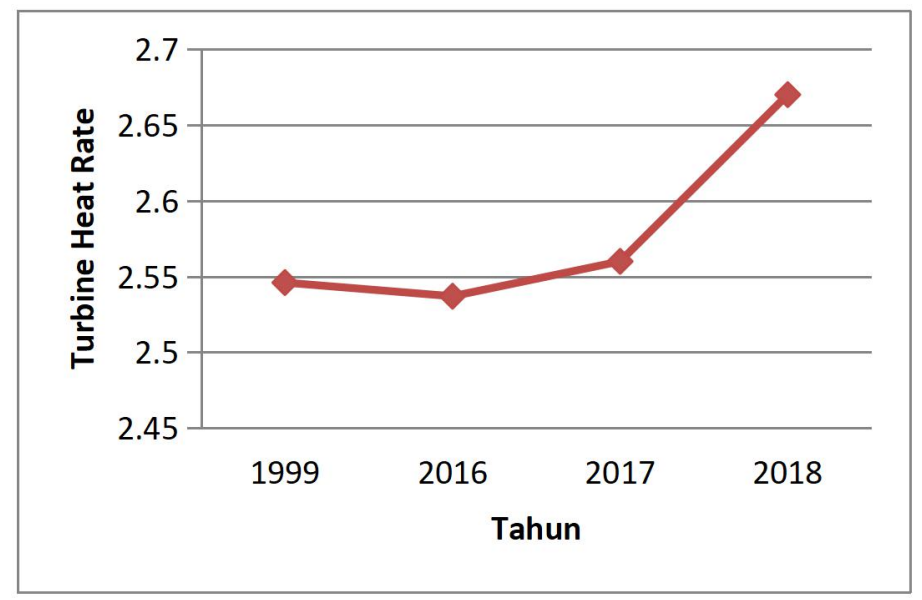

Gambar 4. Grafik Turbine Heat Rate Rata - Rata Per Tahun 


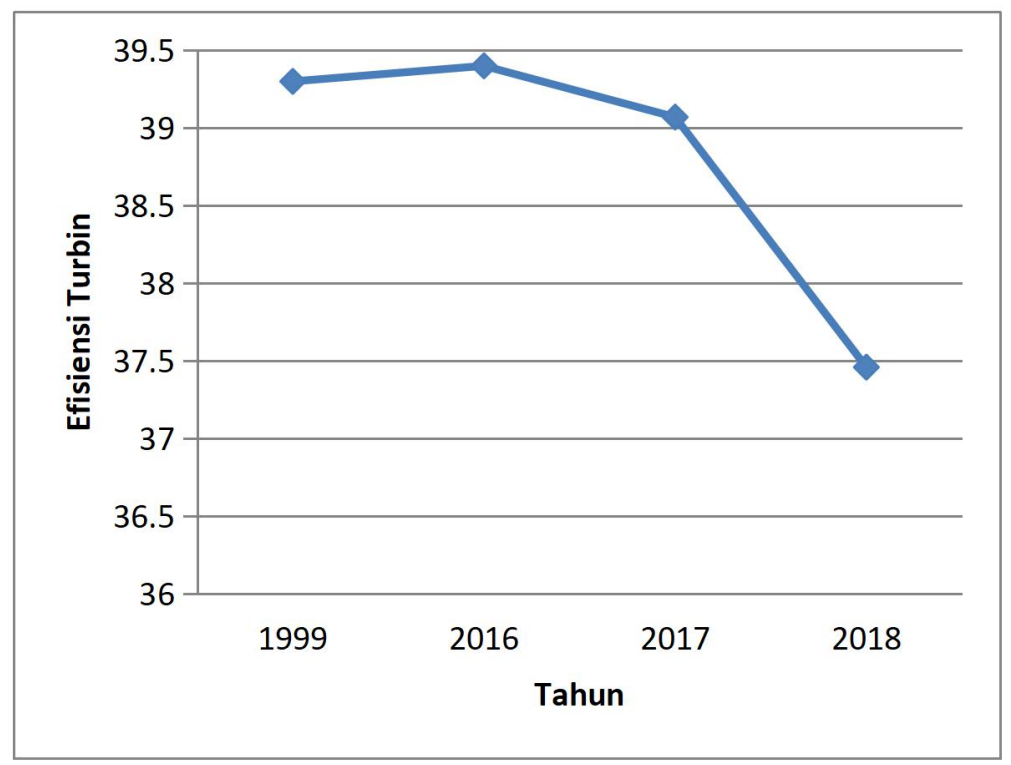

Gambar 5. Grafik Efisiensi Turbin Rata - Rata Per Tahun

\section{PEMBAHASAN}

Dari analisis data yang didapat kinerja pada PLTU PT. Indocement Tunggal Prakarsa Tbk Tarjun P-12 dari Tahun 1999 awal beroperasi dan dilakukannya performance test hingga sekarang Mei 2018 kinerja dari turbin mengalami penurunan dari $39,3 \%$ menjadi $37,46 \%$, terjadinya penurunan kinerja diikuti dengan naiknya heat rate dari turbin uap. Pada tahun 2016 terlihat bahwa efesiensi rata - rata mengalami kenaikan dari tahun 1999, tetapi pada dasarnya efisiensi tahun 2016 mengalami penurunan, hal ini dapat dilihat dari perbandingan efisiensi maksimum pada satu titik di tahun 2016 dengan nilai $41,43 \%$ lebih kecil dari pada efisiensi di satu titik di tahun 1999 yaitu bernilai $42,36 \%$. Selain itu faktor lain adalah banyaknya jumlah pengambilan titik data di tahun 2016 dan 1999 berbeda. Beberapa faktor yang dapat mempengaruhi kinerja dari turbin uap yaitu menurunnya performa peralatan PLTU seperti peralatan pemanas/ Heater air demin diantaranya HP Heater, LP heater, deaerator. Selain itu performa kondensor juga sangat mempengaruhi, karena dikondensor terjadi fase perubahan fluida dari uap menjadi air yang nantinya air tersebut digunakan kembali untuk dipanaskan di boiler menjadi uap superheated untuk memutar turbin.

Pada PLTU PT. Indocement terdapat beberapa kerusakan pada peralatan diantaranya pada HP heater yang terdapat kebocoran pada katup dan pada kondenser terjadi kerusakan pada ball cleaning yang mengakibatkan sistem ball cleaning tidak berfungsi, hal ini dapat mempengaruhi laju perpindahan panas pada pipa - pipa kondensor 


\section{KESIMPULAN}

Dari hasil perhitungan dan analisis nilai turbine heat rate rata - rata PLTU PT Indocement Tunggal Prakarsa Tbk Tarjun Plant 12 berdasarkan performance test pada bulan Agustus 1999 adalah 2,546, bulan April 2016 2,537, bulan Juni 2017 2,56, dan bulan Mei 2018 2,67. Nilai efisiensi turbin rata-rata pada bulan Agustus 1999 adalah 39,30 \%, bulan April 2016 39,43\%, Juni 2017 39,07\%, bulan Mei 2018 37,46 \%. Unjuk kerja turbin PLTU PT Indocement Tunggal Prakarsa Tbk Tarjun Plant 12 terjadi penurunan dari tahun 1999 hingga tahun 2018 sebesar $1,84 \%$.

\section{DAFTAR PUSTAKA}

Boles, Michael A and Yunus A Cengel. 2002. Thermodynamics : An Angineering. Priyaoatmojo, Slamet dan Margana. 2016. "Analisa Efisiensi HRSG Unit 1 di PT PLN (Persero) Sektor Pembangkitan PLTGU Cilegon”. Jurnal Teknik Energi Vol 12 No.2

Putra Iriansyah. 2013 " Mengenal Turbin Uap “ Artikel Mechanical Engineering

Sentosa, Dian Swastaatika. 2008. Session 17 "Steam Turbine Theori "

Sunarwo dan Supriyo. 2015. " Analisa Heat Rate Pada Turbin Uap Berdasarkan Performance Test PLTU Tanjung Jati B Unit 3 “ Jurnal Teknik Energi Vol 11 No. 3.

Supriyanto Eko, dkk. 2014. " Kajian Heat Rate dan Simulasi Menggunakan Software Thermoflow (Studi Kasus PLTU Ombilin Unit 1 dan PLTU Tanjung Jati B Unit 4).

Utility Operation Dept. 2016. Power Plant Overview : Power Station Training and Development. 